\title{
Implementation of the Chronic Disease Care System and its association with health care costs and continuity of care in Korean adults with type 2 diabetes mellitus
}

Woorim Kim ${ }^{1,2}$, Yoon Soo Choy ${ }^{1,2}$, Sang Ah Lee ${ }^{1,2}$ and Eun-Cheol Park ${ }^{2,3^{*}}$ (D)

\begin{abstract}
Background: The Chronic Disease Care System (CDCS) has been implemented in Korea to encourage treatment continuity in chronic disease patients. This study investigated the effect of the introduction of the CDCS on health care costs and continuity of care in individuals with type 2 diabetes mellitus (T2DM).

Methods: The National Health Insurance data from August, 2010 to March, 2012 (pre-policy) and from May, 2012 to December, 2013 (post-policy) were used. Introduction of the CDCS was defined as the intervention. The intervention group consisted of T2DM patients participating in the program and the control group patients not participating in the program. The Difference-in-Differences (DID) method was used to estimate the differences in total health care costs for outpatient services and continuity of care between the intervention and the control group before and after the intervention period.

Results: Implementation of the CDCS was associated with decreased health care costs ( $\beta=-46,877$ Korean Won, $P<0.0001)$ and improved continuity of care $(\beta=0.0536, P<0.0001)$ in the intervention group with adjustment for covariates.

Conclusion: Findings confirm an association between the adoption of the CDCS and reduced health care costs and improved continuity of care. The results reveal the potential benefits of reinforcing effective chronic disease management strategies in reducing health care costs and improving treatment continuity.
\end{abstract}

Keywords: Chronic disease care system, Primary health care, Health care costs, Continuity of care, Treatment continuity, Chronic disease

\section{Background}

Diabetes mellitus is a global public health problem, with the number of affected individuals expected to rise from 360 million in 2011 to 550 million in 2030 [1]. The prevalence of diabetes has also increased from around nine to 11\% between 2011 and 2013 in South Korea, which is alarming because diabetes and its related complications often increase the burden individuals and health care systems experience in terms of health

\footnotetext{
* Correspondence: ECPARK@yuhs.ac

${ }^{2}$ Institute of Health Services Research, Yonsei University, Seoul, Republic of Korea

${ }^{3}$ Department of Preventive Medicine, Yonsei University College of Medicine, 50 Yonsei-ro, Seodaemun-gu, Seoul 120-752, Republic of Korea

Full list of author information is available at the end of the article
}

outcomes and costs $[2,3]$. In fact, previous studies have reported that diabetes act to decrease the health-related quality of life (HRQoL) of affected individuals [4]. Furthermore, diabetes and its related complications are a leading cause of morbidity and mortality in Korea [5].

Specifically, the prevalence type 2 diabetes mellitus (T2DM) has been increasing noticeably at a rate of $7.9 \%$ among Korean adults [6, 7]. As diabetes is chronic in nature and can lead to severe complications, including cardiovascular disease (CVD), retinopathy, nephropathy, neuropathy, peripheral-vascular disease, and cerebrovascular disease, the quality of diabetes treatment is an important issue to address [8]. At the same time, diabetes is also known to cause around 250 million United States dollars

(c) The Author(s). 2018 Open Access This article is distributed under the terms of the Creative Commons Attribution 4.0 International License (http://creativecommons.org/licenses/by/4.0/), which permits unrestricted use, distribution, and reproduction in any medium, provided you give appropriate credit to the original author(s) and the source, provide a link to the Creative Commons license, and indicate if changes were made. The Creative Commons Public Domain Dedication waiver (http://creativecommons.org/publicdomain/zero/1.0/) applies to the data made available in this article, unless otherwise stated. 
(USD) aggregate annual direct costs $[9,10]$. Moreover, patients who develop diabetes related complications are known to require higher levels of medical expenditure [9].

Considering the importance of providing proper disease management to enhance treatment quality and contain costs, the government of Korea introduced the Chronic Disease Care System (CDCS) program in 2012 [11]. The CDCS program aims to enhance care coordination by encouraging patients with T2DM or hypertension to designate a primary care clinic of their choice for continued care [12]. By voluntarily participating in the CDCS program, T2DM patients choose a preferred primary clinic and agree to consistently receive care from the selected institution. Participation assures a reduction of out-of-pocket costs for outpatient services from the regular 30 to $20 \%$ of total costs, along with the provision of health support services, such as consultation and education. Health care providers are separately provided with incentives after assessment by the Health Insurance Review and Assessment Service (HIRA).

The government expects that the CDCS program will improve treatment quality by improving continuity of care, in addition to equipping patients with better disease self-management skills. Implementation of the CDCS program has been expected to enhance continuity of care, which is significant because Korea lacks a personalized general practitioner (GP) based primary care system [13]. Additionally, because continuity of care has been associated with indicators of patient prognoses, including the development of complications, mortality, emergency room visits, and hospital admissions, promoting care coordination is also essential in maintaining health care costs [14]. Therefore, the purpose of this study was to estimate the effect of the CDCS implementation on health care costs and continuity of care in patients with T2DM.

\section{Methods}

\section{Study population}

This study used the Korea National Health Insurance (NHI) cohort data. In Korea, all individuals are covered by either the NHI or Medical Aid and the NHI is known to cover around $98 \%$ of the total population. The NHI cohort data were constructed based on 1,025,340 nationally representative random samples of the entire 2002 population. The sample population equals around $2.2 \%$ of the 46,605,433 residents recorded by the Korean National Health Insurance Service (KNHIS). Data were collected using a systematic sampling method and include all filed medical claims between 2002 and 2013.

Data from August, 2010 to March, 2012 (pre-policy) and from May, 2012 to December, 2013 (post-policy) were used because the CDCS, defined as the intervention, was implemented on April, 2012. Individuals diagnosed primarily of T2DM (International Classification of Diseases version 10 [ICD-10] E11) were included. The control group included T2DM diagnosed individuals not participating in the CDCS program and the intervention group patients who voluntarily opted to participate in the CDCS program.

The study population comprised of adults aged between 20 and 65 years. Older aged individuals were excluded as they have different levels of disease severity and exhibit unalike treatment patterns. Individuals aged 65 or above are also subject to lower levels of cost sharing for outpatient services that cost up to 15,000 Korean Won [KRW, $(1 \mathrm{USD}=1128 \mathrm{KRW})$ ]. Individuals with less than 3 outpatient physician visits were also omitted to ensure consistency in measuring continuity of care. Additionally, Medical Aid beneficiaries were not included as they are subject to different levels of copayment and often have different health care utilization patterns. The final study population consisted of 3388 individuals in the intervention and 14,191 individuals in the control group during the pre-implementation period and 3184 individuals in the intervention and 13,036 individuals in the control group during the post-implementation period.

\section{Variables}

The dependent variables were total health care costs for covered outpatient services and continuity of care. Continuity of care was measured using the usual provider of care (UPC) index, defined as the number of outpatient visits to the most frequently seen physician divided by the total number of outpatient visits [15]. The UPC index concentrates on the number of physicians seen by a patient and the visit ratio of the most frequently seen physician to all visited physicians. All values range between zero and one.

Demographic, socioeconomic, and health related variables were incorporated as covariates. The included variables were age at diagnosis ( 20 to 29,30 to 39,40 to 49 , 50 to 59 , or 60 to 64), sex (male or female), income (low, middle, or high), region (Seoul, metropolitan, or rural), NHI type (occupational or regional), comorbidities measured using the Charlson Comorbidity Index $(0,1,2,3+)$, disability status (no or yes), medication prescription status (none, insulin only, hypoglycemic agent only, or insulin and hypoglycemic agent), and diabetes related complication status (no or yes). Hypoglycemic agents included sulfonylureas, metformin, alpha glucosidase inhibitors, and thiazolidinedione. Complications refer to retinopathy, nephropathy, neuropathy, peripheral vascular disease, cerebrovascular disease, and cardiovascular disease (CVD) [8].

\section{Statistical analysis}

Quantitative data at baseline and follow up were examined using the chi-square test. The Difference-in-Differences 
(DID) method was utilized to estimate differences in total health care costs and continuity of care between the intervention and the control group before and after the intervention period. The DID method is a quasi-experimental method that focuses on capturing effects related to a certain event through time between the control and the intervention group [16]. The DID specification of this study were $y_{i=\beta_{0}+\beta_{1} \cdot \text { time }_{i}+\gamma \cdot \text { group }_{i}+\delta \text { group }_{i} \text {.time }}+\varepsilon_{i}$. In this regression analysis, $\beta_{0}$ measures the mean outcome of the control group at baseline, $\beta_{0}+\beta_{1}$ the mean outcome of the control group at follow up, $\gamma$ the difference between the control and the intervention group at baseline, $\beta_{0}+\gamma$ the mean outcome of the intervention group at baseline, $\beta_{0}+\beta_{1}+\gamma+\delta$ the mean outcome of the intervention group at follow up, $\delta$ the DID of the intervention, and $\varepsilon_{i}$ the random error.

Both adjusted and unadjusted analysis were carried out. All calculated $P$ values were two sided, considered significant at $<0.05$. Analysis was performed using the SAS software, version 9.4 (SAS Institute, Cary, NC, USA).

\section{Results}

Table 1 shows the general characteristics of the study participants at baseline and follow-up. At the pre-implementation period, a total of 3388 individuals were included in the intervention group and 14,191 individuals in the control group. Similarly, at post-implementation period, 3184 individuals were included in the intervention group and 13,036 individuals in the control group. Characteristics were generally similar between the control and the intervention group, although the control group consisted of a higher percentage of males and a lower percentage of low income individuals. The control group also had a higher proportion of individuals with disability and those diagnosed with diabetes related complications.

Table 2 presents the results of the DID model. The effect of the intervention on health care cost was shown through the coefficient of the interaction term post-policy*intervention. Model 1 reveals the effect of the intervention without adjustment for covariates and model 2 with adjustment for covariates. In terms of health care costs, the coefficient of model $1(\beta=-$ 47,523 KRW, $P<0.0001)$ and model $2(\beta=-46,877$ KRW, $P<0.0001)$ were statistically significant. This implies a positive relationship between implementation of the CDCS and reduced health care costs for covered outpatient services. Likewise, regarding continuity of care, the coefficient of the interaction term post-policy*intervention was significant in model $1(\beta=$ 0.0537, $\mathrm{P}<0.0001)$ and model $2(\beta=0.0536, \mathrm{P}<0.0001)$. The results infer that the adoption of the CDCS was associated with improved continuity of care.

\section{Discussion}

This study investigated the impact of the CDCS on health care costs and continuity of care in Korean adults diagnosed with T2DM. The findings reveal that implementation of the CDCS was associated with reduced expenditures for covered outpatient services and modest improvements in continuity of care. The presented results are in accordance with the expectations of the government, which aimed to incentivize treatment continuity because enhanced coordination has been known to improve quality of care and patient outcomes, which in turn acts to impact the level of health care expenditures [17].

Improvements in continuity of care found in this study are noteworthy because establishing an effective long-term care management plan and improving patient adherence is important in managing chronic diseases. In fact, because chronic diseases cannot be fully cured, patients need to be constantly monitored and well equipped with self-management skills [18]. By improving continuity of care, which familiarizes physicians to patient history, better monitoring of glycemic levels and management of disease related complications can be achieved [19]. At the same time, generating physician-patient trust has also been demonstrated to advance treatment adherence [20]. Correspondingly, previous studies have shown that enhanced treatment continuity can improve patient satisfaction and quality of life, reduce emergency department visits and hospitalizations related to complications, and improve patient outcomes $[19,21,22]$. However, because the primary care system of Korea generally does not function to promote continuity or coordination, many patients are often poorly educated on diabetes-related self-management skills [23]. In fact, the percentage of patients successfully carrying out glucose management have decreased from around 34 to $23 \%$ between 2005 and 2014, and almost half of male diabetes patients are reported to smoke [24]. Under such circumstances, implementation of the CDCS may have aided to improve treatment continuity in T2DM patients.

According to the study results, implementation of the CDCS was also related to decreased health care costs for covered outpatient services. Occurrences of T2DM and its related complications have consistently been noted as factors that escalate health care costs $[25,26]$. In Korea, macro and micro vascular complications in T2DM patients have specifically been reported to cause higher levels of annual direct medical costs, with expenditures increasing with the number of complications [9]. By incentivizing diabetes patients to utilize primary clinics instead of secondary or tertiary hospitals, the CDCS may have acted to decrease diabetes related health care expenditures by promoting a more effective use of health 
Table 1 Characteristics of the intervention and the control group before and after policy implementation

\begin{tabular}{|c|c|c|c|c|c|c|c|c|}
\hline \multirow[b]{3}{*}{ Total } & \multicolumn{4}{|c|}{ Pre-implementation period } & \multicolumn{4}{|c|}{ Post-implementation period } \\
\hline & \multicolumn{2}{|c|}{ Control group } & \multicolumn{2}{|c|}{ Intervention group } & \multicolumn{2}{|c|}{ Control group } & \multicolumn{2}{|c|}{ Intervention group } \\
\hline & 14,191 & $(80.7)$ & 3388 & $(19.3)$ & 13,036 & $(80.4)$ & 3184 & (19.6) \\
\hline \multicolumn{9}{|l|}{ Age } \\
\hline $20-29$ & 144 & $(1.0)$ & 26 & $(0.8)$ & 94 & $(0.7)$ & 15 & $(0.5)$ \\
\hline $30-39$ & 928 & $(6.5)$ & 193 & $(5.7)$ & 643 & $(4.9)$ & 112 & $(3.5)$ \\
\hline $40-49$ & 3699 & $(26.1)$ & 883 & $(26.1)$ & 2856 & $(21.9)$ & 651 & (20.4) \\
\hline $50-59$ & 7183 & $(50.6)$ & 1780 & $(52.5)$ & 6238 & $(47.9)$ & 1580 & (49.6) \\
\hline $60-64$ & 2237 & $(15.8)$ & 506 & $(14.9)$ & 3205 & $(24.6)$ & 826 & (25.9) \\
\hline \multicolumn{9}{|l|}{ Sex } \\
\hline Male & 8911 & $(62.8)$ & 2063 & $(60.9)$ & 8252 & $(63.3)$ & 1935 & $(60.8)$ \\
\hline Female & 5280 & $(37.2)$ & 1325 & (39.1) & 4784 & $(36.7)$ & 1249 & (39.2) \\
\hline \multicolumn{9}{|l|}{ Income } \\
\hline Low & 4241 & $(29.9)$ & 1097 & (32.4) & 3536 & $(27.1)$ & 976 & (30.7) \\
\hline Middle & 4033 & $(28.4)$ & 1055 & $(31.1)$ & 3544 & $(27.2)$ & 967 & (30.4) \\
\hline High & 5219 & $(36.8)$ & 1230 & $(36.3)$ & 5208 & $(40.0)$ & 1239 & (38.9) \\
\hline \multicolumn{9}{|l|}{$\mathrm{NHI}$ type } \\
\hline Occupational & 8122 & $(57.2)$ & 2016 & $(59.5)$ & 7725 & $(59.3)$ & 1985 & (62.3) \\
\hline Regional & 5371 & $(37.8)$ & 1366 & $(40.3)$ & 4563 & $(35.0)$ & 1197 & (37.6) \\
\hline \multicolumn{9}{|l|}{ Region } \\
\hline Seoul & 2670 & (18.8) & 562 & (16.6) & 2402 & $(18.4)$ & 521 & $(16.4)$ \\
\hline Metropolitan & 3782 & $(26.7)$ & 1006 & $(29.7)$ & 3423 & $(26.3)$ & 963 & $(30.2)$ \\
\hline Rural & 7739 & $(54.5)$ & 1820 & $(53.7)$ & 7211 & $(55.3)$ & 1700 & (53.4) \\
\hline \multicolumn{9}{|l|}{ Charlson Comorbidity Index } \\
\hline 0 & 711.0 & $(5.0)$ & 149 & $(4.4)$ & 568.0 & $(4.4)$ & 115.0 & (3.6) \\
\hline 1 & 6765 & $(47.7)$ & 1657 & $(48.9)$ & 6187 & $(47.5)$ & 1604 & $(50.4)$ \\
\hline 2 & 2573 & $(18.1)$ & 664 & (19.6) & 2363 & $(18.1)$ & 611 & $(19.2)$ \\
\hline $3+$ & 4142 & $(29.2)$ & 918 & $(27.1)$ & 3918.0 & $(30.1)$ & 854.0 & $(26.8)$ \\
\hline \multicolumn{9}{|l|}{ Disability } \\
\hline No & 12,832 & $(90.4)$ & 3139 & $(92.7)$ & 11,684 & $(89.6)$ & 2940 & $(92.3)$ \\
\hline Yes & 1359 & (9.6) & 249 & $(7.3)$ & 1352 & $(10.4)$ & 244 & $(7.7)$ \\
\hline \multicolumn{9}{|l|}{ Medication } \\
\hline None & 546 & (3.8) & 39 & $(1.2)$ & 476 & $(3.7)$ & 30 & $(0.9)$ \\
\hline Insulin only & 183 & $(1.3)$ & 45 & (1.3) & 163 & $(1.3)$ & 36 & $(1.1)$ \\
\hline Hypoglycemic agent only & 12,530 & $(88.3)$ & 3147 & $(92.9)$ & 11,544 & $(88.6)$ & 2964 & (93.1) \\
\hline Insulin \& hypoglycemic agent & 932 & (6.6) & 157 & (4.6) & 853 & $(6.5)$ & 154 & $(4.8)$ \\
\hline \multicolumn{9}{|l|}{ Complication } \\
\hline No & 8258 & $(58.2)$ & 2050 & $(60.5)$ & 7626 & $(58.5)$ & 1966 & $(61.7)$ \\
\hline Yes & 5933 & $(41.8)$ & 1338 & $(39.5)$ & 5410 & $(41.5)$ & 1218 & (38.3) \\
\hline
\end{tabular}

*NHI=National Health Insurance

Hypoglycemic agents include sulfonylureas, metformin, alpha glucosidase inhibitors, and thiazolidinedione

care resources at the national level. Moreover, the CDCS could have led to reductions in health care costs by inducing treatment continuity considering that better continuity has been previously associated with decreases in health care utilization and expenses [19]. In fact, previous findings have conveyed that poor treatment continuity can escalate risks for diabetic complications and induce heavier health care utilization, which naturally necessitates increases in medical expenditure [19]. Frequent doctor switching may also lead to interruptions 
Table 2 Differential changes in spending and continuity of care between the intervention and the control group

\begin{tabular}{|c|c|c|c|c|c|c|c|c|c|c|c|c|}
\hline & \multicolumn{6}{|c|}{ Total cost } & \multicolumn{6}{|c|}{ Continuity of Care } \\
\hline & \multicolumn{3}{|l|}{ Model 1} & \multicolumn{3}{|l|}{ Model 2} & \multicolumn{3}{|c|}{ Model 1} & \multicolumn{3}{|l|}{ Model 2} \\
\hline & $\bar{\beta}$ & SE & $p$-value & $\bar{\beta}$ & SE & $p$-value & $\beta$ & SE & $p$-value & $\bar{\beta}$ & SE & $p$-value \\
\hline Pre-policy & Ref & & & Ref & & & Ref & & & Ref & & \\
\hline Post-policy & $-15,419$ & 3639 & $<.0001$ & $-12,789$ & 3665 & 0.0005 & 0.0055 & 0.0016 & 0.0009 & 0.0050 & 0.0017 & 0.0025 \\
\hline Control group & Ref & & & Ref & & & Ref & & & Ref & & \\
\hline Intervention group & -9589 & 3078 & 0.0018 & -5895 & 3014 & 0.0505 & 0.0093 & 0.0016 & $<.0001$ & 0.0093 & 0.0016 & $<.0001$ \\
\hline Post-policy*Intervention group & $-47,523$ & 4700 & $<.0001$ & $-46,877$ & 4724 & $<.0001$ & 0.0537 & 0.0025 & $<.0001$ & 0.0536 & 0.0026 & $<.0001$ \\
\hline \multicolumn{13}{|l|}{ Age } \\
\hline $20-29$ & & & & Ref & & & & & & Ref & & \\
\hline $30-39$ & & & & $-63,369$ & 31,611 & 0.045 & & & & 0.0070 & 0.0123 & 0.5706 \\
\hline $40-49$ & & & & $-70,130$ & 31,402 & 0.0255 & & & & 0.0118 & 0.0119 & 0.3201 \\
\hline $50-59$ & & & & $-69,671$ & 31,320 & 0.0261 & & & & 0.0130 & 0.0118 & 0.2729 \\
\hline $60-64$ & & & & $-91,574$ & 31,416 & 0.0036 & & & & 0.0139 & 0.0119 & 0.2446 \\
\hline \multicolumn{13}{|l|}{ Sex } \\
\hline Male & & & & Ref & & & & & & Ref & & \\
\hline Female & & & & 28,995 & 5011 & $<.0001$ & & & & -0.0037 & 0.0019 & 0.0481 \\
\hline \multicolumn{13}{|l|}{ Income } \\
\hline Low & & & & Ref & & & & & & Ref & & \\
\hline Middle & & & & 6009 & 5507 & 0.2751 & & & & 0.0003 & 0.0023 & 0.9045 \\
\hline High & & & & 7620 & 4928 & 0.122 & & & & 0.0085 & 0.0021 & $<.0001$ \\
\hline \multicolumn{13}{|l|}{$\mathrm{NHI}$ type } \\
\hline Occupational & & & & Ref & & & & & & Ref & & \\
\hline Regional & & & & 6311 & 4486 & 0.1594 & & & & -0.0080 & 0.0018 & $<.0001$ \\
\hline \multicolumn{13}{|l|}{ Region } \\
\hline Seoul & & & & Ref & & & & & & Ref & & \\
\hline Metropolitan & & & & 5500 & 6125 & 0.3693 & & & & -0.0052 & 0.0027 & 0.0525 \\
\hline Rural & & & & 6885 & 5678 & 0.2253 & & & & -0.0049 & 0.0024 & 0.0394 \\
\hline \multicolumn{13}{|l|}{ Charlson Comorbidity Index } \\
\hline 0 & & & & Ref & & & & & & Ref & & \\
\hline 1 & & & & $-13,878$ & 6915 & 0.0448 & & & & -0.0201 & 0.0036 & $<.0001$ \\
\hline 2 & & & & -4345 & 8483 & 0.6086 & & & & -0.0196 & 0.0040 & $<.0001$ \\
\hline $3+$ & & & & 10,013 & 7837 & 0.2013 & & & & -0.0420 & 0.0039 & $<.0001$ \\
\hline \multicolumn{13}{|l|}{ Disability } \\
\hline No & & & & Ref & & & & & & Ref & & \\
\hline Yes & & & & 35,482 & 10,247 & 0.0005 & & & & -0.0101 & 0.0035 & 0.0035 \\
\hline \multicolumn{13}{|l|}{ Medication } \\
\hline None & & & & Ref & & & & & & Ref & & \\
\hline Insulin only & & & & $-74,185$ & 39,588 & 0.0609 & & & & -0.0375 & 0.0097 & 0.0001 \\
\hline Hypoglycemic agent only & & & & $-134,483$ & 21,686 & $<.0001$ & & & & -0.0320 & 0.0040 & $<.0001$ \\
\hline Insulin \& hypoglycemic agent & & & & 3280 & 27,210 & 0.9041 & & & & -0.0662 & 0.0057 & $<.0001$ \\
\hline \multicolumn{13}{|l|}{ Complication } \\
\hline No & & & & Ref & & & & & & Ref & & \\
\hline Yes & & & & 35,446 & 4322 & $<.0001$ & & & & -0.0042 & 0.0019 & 0.0304 \\
\hline
\end{tabular}

${ }^{*} \mathrm{NHI}=$ National Health Insurance

Hypoglycemic agents include sulfonylureas, metformin, alpha glucosidase inhibitors, and thiazolidinedione 
in medicine prescription, negatively interfering with patient monitoring and cultivation of self-management skills [3]. As provision of higher quality care is important in managing T2DM patients, this study offers insight by revealing the potential benefits of employing policies that promote a more effective use of health care resources [27].

The findings of this study should be interpreted while accounting for the following limitations. First, not all primary clinics participated in the CDCS program. The program participation rate was around $63 \%$ in 2014 . Hence, some individuals may have faced difficulties in accessing primary clinics that offer the CDCS program. Second, reductions in total health care costs may have been partially affected by the policy implemented in 2012 that reduced total pharmaceutical costs at an average of around 14\%. However, this study did adjust for pharmaceutical prescription status to partially overcome this limitation. Third, health care costs measured in this study only accounted for services reimbursed by the KNHIS. As Korea uses both a positive and a negative list system to determine service reimbursement status, a grey zone of non-covered services that fully depend on patient out of pocket costs exist. As this study only considered costs for covered services due to data limitation, the results cannot be seen as a reflection of total T2DM related costs. Fourth, medical illnesses were identified and categorized solely based on the ICD-10 code. Thus, there may have been some inaccuracies in diagnosis coding. Fifth, pharmaceuticals were classified only based on prescription status, which does not necessarily imply consumption or medical adherence. Last, this study may not have been able to adjust for all potential risk factors, which implies that there may be a possibility of residual confounding. However, despite the limitations stated above, this study is noteworthy as it provides evidence on how implementation of the CDCS affected health care costs and continuity of care in T2DM diagnosed patients.

\section{Conclusion}

This study analyzed the effect of the implementation of the CDCS on health care costs for outpatient services and continuity of care in T2DM patients. The results confirm an association between the adoption of the CDCS and reduced health care costs and improved continuity of care. The discoveries offer insight by signifying the potential benefits of employing effective chronic disease management strategies in reducing health care costs and improving treatment continuity in T2DM patients.

\section{Abbreviations}

CDCS: Chronic Disease Care System; CVD: Cardiovascular disease; DID: Difference in Differences; GP: General practitioner; ICD-10: International Classification of Diseases version 10; KNHIS: Korean National Health Insurance Service; KRW: Korean Won; NHI: National Health Insurance; T2DM: Type 2 Diabetes Mellitus; UPC: Usual provider of care
Acknowledgments

None to declare.

Funding

None to declare.

Availability of data and materials

The NHI data can be obtained after application and approval by the KNHIS.

\section{Author's contributions}

W.K. and E.C.P designed the study, performed the statistical analysis, and wrote the manuscript. W.K., E.C.P., Y.S.C., and S.A.L. contributed to the discussion and reviewed and edited the manuscript. E.C.P is the guarantor of this work and as such, had full access to all of the data. E.C.P assumes responsibility for the integrity of the data and the accuracy of the data analysis.

\section{Ethics approval and consent to participate}

The NHI data are secondary data and does not contain any private information. As the obtained data were anonymized and de-identified prior to analysis, the study protocol was not subjected to review by the ethics committee. This study follows the operational principles of the Declaration of Helsinki.

Consent for publication

All authors give consent to publish this article.

Competing interests

None to declare.

\section{Publisher's Note}

Springer Nature remains neutral with regard to jurisdictional claims in published maps and institutional affiliations.

\section{Author details}

${ }^{1}$ Department of Public Health, Graduate School, Yonsei University, Seoul, Republic of Korea. ${ }^{2}$ Institute of Health Services Research, Yonsei University, Seoul, Republic of Korea. ${ }^{3}$ Department of Preventive Medicine, Yonsei University College of Medicine, 50 Yonsei-ro, Seodaemun-gu, Seoul 120-752, Republic of Korea.

Received: 9 July 2018 Accepted: 11 December 2018

Published online: 22 December 2018

\section{References}

1. Whiting DR, Guariguata L, Weil C, Shaw J. IDF diabetes atlas: global estimates of the prevalence of diabetes for 2011 and 2030. Diabetes Res Clin Pract. 2011;94(3):311-21.

2. Alva ML, Gray A, Mihaylova B, Leal J, Holman RR. The impact of diabetesrelated complications on healthcare costs: new results from the UKPDS (UKPDS 84). Diabet Med. 2015:32(4):459-66.

3. Liao PJ, Lin ZY, Huang JC, Hsu KH. The relationship between type 2 diabetic Patients' early medical care-seeking consistency to the same clinician and health care system and their clinical outcomes. Medicine. 2015;94(7).

4. Rajan N, Boye KS, Gibbs M, Lee YJ, Davey P, Ball M, Babineaux SM. Utilities for Type 2 diabetes treatment-related attributes in a south Korean and Taiwanese population. Value Health Reg Issues. 2016;9:67-71.

5. Statistics Korea: Annual report on the vital statistics in Korea. In. Seoul, Republic of Korea: Statistics Korea; 2014.

6. Koo BK, Lee CH, Yang BR, Hwang SS, Choi NK. The incidence and prevalence of diabetes mellitus and related atherosclerotic complications in Korea: a National Health Insurance Database Study. PLoS One. 2014;9(10): e110650.

7. Noh J. The diabetes epidemic in Korea. Endocrinol Metab (Seoul). 2016; 31(3):349-53.

8. Han E, Suh DC, Lee SM, Jang S. The impact of medication adherence on health outcomes for chronic metabolic diseases: a retrospective cohort study. Res Soc Admin Pharm. 2014;10(6):E87-98.

9. Kim TH, Chun KH, Kim HJ, Han SJ, Kim DJ, Kwak J, Kim YS, Woo JT, Park Y, Nam $M$, et al. Direct medical costs for patients with type 2 diabetes and 
related complications: a prospective cohort study based on the Korean National Diabetes Program. J Korean Med Sci. 2012;27(8):876-82.

10. Rhee SY, Chon S, Kwon MK, Park le B, Ahn KJ, Kim IJ, Kim SH, Lee HW, Koh $\mathrm{KS}$, Kim DM, et al. Prevalence of chronic complications in korean patients with type 2 diabetes mellitus based on the korean national diabetes program. Diabetes Metab J. 2011;35(5):504-12.

11. Hwang B-D. The attitude of medical practitioners to the chronic disease care system. Korean J Health Serv Manage. 2012;6(2):193-200.

12. Park YH. Strategy for noncommunicable disease control and prevention. J Korean Med Assoc. 2014;57(10):808-14.

13. Hussey PS, Schneider EC, Rudin RS, Fox DS, Lai J, Pollack CE. Continuity and the costs of care for chronic disease. JAMA Intern Med. 2014;174(5):742-8.

14. Thanh NX, Rapoport J. Health services utilization of people having and not having a regular doctor in Canada. Int J Health Plann Manag. 2016.

15. Jee SH, Cabana MD. Indices for continuity of care: a systematic review of the literature. Med Care Res Rev. 2006;63(2):158-88.

16. Villa J. Simplifying the estimation of difference in differences treatment effects with Stata. In: 22(1); 2013. p. 59-70.

17. Chen CC, Tseng $\mathrm{CH}$, Cheng SH. Continuity of care, medication adherence, and health care outcomes among patients with newly diagnosed type 2 diabetes: a longitudinal analysis. Med Care. 2013;51(3):231-7.

18. Rijken M, Bekkema N, Boeckxstaens P, Schellevis FG, De Maeseneer JM Groenewegen PP. Chronic disease management Programmes: an adequate response to patients' needs? Health Expect. 2014;17(5):608-21.

19. Chen CC, Chen SH. Better continuity of care reduces costs for diabetic patients. Am J Manag Care. 2011;17(6):420-7.

20. Leopold N, Cooper J, Clancy C. Sustained partnership in primary care. J Fam Pract. 1996:42(2):129-37.

21. Gulliford MC, Naithani S, Morgan M. Continuity of care and intermediate outcomes of type 2 diabetes mellitus. Fam Pract. 2007;24(3):245-51.

22. Lin W, Huang IC, Wang SL, Yang MC, Yaung CL. Continuity of diabetes care is associated with avoidable hospitalizations: evidence from Taiwan's National Health Insurance scheme. Int J Qual Health C. 2010;22(1):3-8.

23. Choi YJ, Kim HC, Kim HM, Park SW, Kim J, Kim DJ. Prevalence and management of diabetes in Korean adults: Korea National Health and nutrition examination surveys 1998-2005. Diabetes Care. 2009;32(11):2016-20.

24. Park SW, Kim DJ, Min KW, Baik SH, Choi KM, Park IB, Park JH, Son HS, Ahn CW, Oh J-Y, et al. Current status of diabetes Management in Korea Using National Health Insurance Database. Diabetes Metab J. 2007;31(4):362-7.

25. Kim DJ. The epidemiology of diabetes in Korea. Diabetes Metab J. 2011; 35(4):303-8.

26. Yoo IS. The study of health care utilization and direct medical cost in the diabetes mellitus client. J Converg Cult Tech. 2015;1(4):87-101.

27. Chan JC, Cho NH, Tajima N, Shaw J. Diabetes in the Western Pacific region-past, present and future. Diabetes Res Clin Pract. 2014;103(2):244-55.

Ready to submit your research? Choose BMC and benefit from:

- fast, convenient online submission

- thorough peer review by experienced researchers in your field

- rapid publication on acceptance

- support for research data, including large and complex data types

- gold Open Access which fosters wider collaboration and increased citations

- maximum visibility for your research: over $100 \mathrm{M}$ website views per year

At $\mathrm{BMC}$, research is always in progress.

Learn more biomedcentral.com/submissions 